\title{
Evapotranspiration Partitioning in CMIP5 Models: Uncertainties and Future Projections $\mathscr{O}$
}

\author{
AleXIs BERG \\ Department of Civil and Environmental Engineering, Princeton University, Princeton, New Jersey \\ JUSTIN SHEFFIELD \\ Department of Geography, University of Southampton, Southampton, United Kingdom
}

(Manuscript received 6 September 2018, in final form 28 January 2019)

\begin{abstract}
Evapotranspiration (ET) is a key process affecting terrestrial hydroclimate, as it modulates the land surface carbon, energy, and water budgets. Evapotranspiration mainly consists of the sum of three components: plant transpiration, soil evaporation, and canopy interception. Here we investigate how the partitioning of ET into these three main components is represented in CMIP5 model simulations of present and future climate. A large spread exists between models in the simulated mean present-day partitioning; even the ranking of the different components in the global mean differs between models. Differences in the simulation of the vegetation leaf area index appear to be an important cause of this spread. Although ET partitioning is not accurately known globally, existing global estimates suggest that CMIP5 models generally underestimate the relative contribution of transpiration. Differences in ET partitioning lead to differences in climate characteristics over land, such as land-atmosphere fluxes and near-surface air temperature. On the other hand, CMIP5 models simulate robust patterns of future changes in ET partitioning under global warming, notably a marked contrast between decreased transpiration and increased soil evaporation in the tropics, whereas transpiration and evaporation both increase at higher latitudes and both decrease in the dry subtropics. Idealized CMIP5 simulations from a subset of models show that the decrease in transpiration in the tropics largely reflects the stomatal closure effect of increased atmospheric $\mathrm{CO}_{2}$ on plants (despite increased vegetation from $\mathrm{CO}_{2}$ fertilization), whereas changes at higher latitudes are dominated by radiative $\mathrm{CO}_{2}$ effects, with warming and increased precipitation leading to vegetation increase and simultaneous (absolute) increases in all three ET components.
\end{abstract}

\section{Introduction}

Evaporation of water from the land to the atmosphere is a key process regulating and coupling the carbon, energy, and water budgets of the land surface. As such, it is critical that land evaporation be represented accurately in model simulations of the physical climate and in Earth system model simulations of the coupled carbon cycle and climate system.

Representing the land-atmosphere fluxes of water and energy in response to available energy (e.g., radiation) and water input (e.g., precipitation) is the primary

Supplemental information related to this paper is available at the Journals Online website: https://doi.org/10.1175/JCLI-D-180583.s1.

Corresponding author: Alexis Berg, ab5@princeton.edu task of the land surface component of climate models. The representation of land evaporation is challenging because part of this flux occurs through vegetation (plant transpiration) and part of it occurs through abiotic processes. The latter include evaporation from bare soil and evaporation from water intercepted and stored on the canopy following precipitation events (hereafter referred to as canopy interception). These fluxes result from different processes, and thus respond differently to environmental drivers. For instance, canopy interception depends on the structural properties of vegetation and precipitation characteristics (e.g., Miralles et al. 2010); transpiration differs from soil evaporation in that plants have access to deeper reservoirs of water, and stomatal conductance can vary in response to specific environmental drivers like atmospheric $\mathrm{CO}_{2}$ and humidity. As a result, the total flux, called evapotranspiration (ET), is usually represented in land surface 
models as the sum of these three main terms, calculated separately (other more minor terms in the annual mean include evaporation from snow, and evaporation from open water on land such as lakes and rivers).

Because of the complexity of the land-atmosphere interface, the historical lack of observational constraints on land-atmosphere exchanges, and the different modeling choices made in the representation and parameterization of land surface processes, climate models show large differences in their simulation of landatmosphere fluxes, including ET (e.g., Mueller and Seneviratne 2014, and references therein). Much research has been directed over the past decade toward evaluating the representation of ET in climate models, based on global land ET products derived from observations, such as remote sensing data, upscaled in situ measurements, and/or land surface models driven by observations (e.g., Mueller et al. 2013). Perhaps less attention has been devoted, until recently, to assessing in more detail how models represent the partitioning of ET into its three main components. An obvious challenge to such an assessment is that the partitioning of ET is not accurately known at the global scale: large-scale, extensive observations of the different ET components are simply not available. Indeed, ET components can be measured in situ by different techniques, such as through a combination of stable isotope, sap flow, and eddy covariation techniques (Williams et al. 2004; Kool et al. 2014); however, such observations remain sparse for now and are affected by methodological uncertainties. Because ET cannot be directly sensed from space, global ET products based on remote sensing include some amount of modeling to retrieve ET based on observable variables; because of different modeling assumptions, they produce vastly different estimates of ET partitioning (Miralles et al. 2016). More recently, global estimates of the fraction of transpiration in ET have been proposed, based on different approaches including isotopic techniques (Jasechko et al. 2013; CoendersGeritts et al. 2014; Good et al. 2015), as well as available direct observations upscaled based on global vegetation distribution (Wei et al. 2017). Schlesinger and Jasechko (2014) and Wei et al. (2017) provide reviews of all these approaches, as well as of available in situ observations (Wang et al. 2014): while they indicate a wide range of estimates for the global fraction of transpiration, from $25 \%$ to $90 \%$, estimates coalesce around a central value of around $60 \%$, which thus arguably represents our best knowledge, at this point, of the global role of transpiration. By complementarity, this also constrains the relative size of the soil evaporation and canopy interception components. Independent global estimates of canopy interception over forests have been proposed that are broadly consistent with such values (e.g., $10 \%-$ $20 \%$ of precipitation is intercepted by forest canopies; Miralles et al. 2010). However, the exact global role of soil evaporation and canopy interception remains uncertain as well. It should be noted that on a regional scale soil evaporation and canopy interception may be significant or even dominant terms. Overall, knowledge of ET partitioning at the global scale remains poorly constrained, beyond the general orders of magnitude of the different terms.

In the present study, we focus on investigating the representation of ET partitioning in current-generation climate models, using the models from phase 5 of the Coupled Model Intercomparison Project (CMIP5). Some studies have analyzed ET partitioning within a given climate model (e.g., Lawrence et al. 2007). More recently, Lian et al. (2018) and Chang et al. (2018) have compared the fraction of transpiration in ET from climate models to site measurements, and have analyzed systematic biases. Here, we explore model spread in the representation of the different terms of ET partitioning. Because of the limitation of global observational constraints on the different ET components, we do not seek here to explicitly evaluate ET partitioning in climate models in detail [beyond the central estimate of transpiration fraction from Wei et al. (2017)]. Rather, we aim to document the diversity in ET partitioning across CMIP5 models. Because ET partitioning is strongly linked to vegetation (e.g., Wang et al. 2010, 2014), we explore how this diversity is linked to differences in simulated vegetation across models. We also explore the potential relationships between the spread in ET partitioning and general aspects of the simulated climate in these models. Finally, we investigate what future changes in partitioning models simulate in response to anthropogenic forcing and global warming and what factors are driving these changes.

\section{Data and methods}

We use monthly outputs from historical and representative concentration pathway 8.5 (RCP8.5; Riahi et al. 2011) simulations from the CMIP5 experiment. We choose the RCP8.5 simulation to maximize the projected changes in the future and the potential differences between models. We analyze the following variables: total ET and its components (transpiration, soil evaporation, and canopy interception) and surface climate variables such as $2-\mathrm{m}$ temperature and turbulent and radiative land-atmosphere fluxes. For vegetation data, we focus primarily on the leaf area index (LAI). Indeed, LAI is the primary vegetation-related variable considered in studies that investigate the influence of 
vegetation on ET partitioning (e.g., Wang et al. 2014), as the surface area of vegetation directly affects transpiration and canopy interception, and indirectly soil evaporation (by covering the ground). Other vegetation properties that may differ across models may influence ET partitioning (e.g., stomatal conductance) but are not analyzed here. Data for the historical simulations are analyzed over 1950-2005, and for RCP8.5 over 20712100. For models for which several ensemble members are available, we only use the first member (" $\mathrm{r} 1$ " in the CMIP5 archive). We compute annual means as well as summertime means [summertime being defined as June-August (JJA) in the Northern Hemisphere and December-February (DJF) in the Southern Hemisphere].

ET outputs from the historical simulations were available from 48 CMIP5 models. Not all models provided all three variables of ET partitioning, either because of omissions or because these variables are simply not provided by the models themselves, or because of errors in the reporting (e.g., the sum of two components was reported under one variable). Where possible, outputs were corrected to account for obvious errors in reporting (e.g., one variable was subtracted from the sum of the two in the other file). Overall, complete ET partitioning was available for 32 models from the historical simulations. For the RCP8.5 simulations, 24 models provided ET partitioning. LAI was available for 30 models in the present, and 27 models in the future. Atmospheric and land-atmosphere flux variables were typically available for more than 40 models. Models used are listed in Table $\mathrm{S} 1$ in the online supplemental material.

To analyze the relationship between ET partitioning and other aspects of model simulations, such as vegetation or surface climate, we compute cross-model (Pearson) correlations. That is, for a given pair of variables, we compute the correlation across models between long-term means for these variables, on a pixel per pixel basis. Note that the ensembles of models available do not necessarily overlap similarly for each pair of variables; in the interest of maximizing the number of models used in these correlations (given the overall low number of available models), for each variable that we cross with ET partitioning, we use the maximum number of common models available. Thus, rather than having a common set of models for the whole analysis, the number of models considered for different combinations of variables differs slightly; given that the number of models to be included in these correlations is not large, we favor including as many models as possible in our analysis (the number of models used is indicated in each figure's caption).

Finally, we also analyze outputs from idealized singleforcing CMIP5 experiments meant to separate the total effect of atmospheric $\mathrm{CO}_{2}$ increase on climate into the radiative effect of $\mathrm{CO}_{2}$ on the atmosphere and the physiological effect of $\mathrm{CO}_{2}$ on vegetation. In the control simulation (1pctCO2 in CMIP5 terminology), both the atmospheric model and the land surface scheme of a climate model are subjected to a $1 \%$ annual increase of atmospheric $\mathrm{CO}_{2}$ starting from preindustrial levels $(284 \mathrm{ppm})$ and lasting 140 years (ending at $1132 \mathrm{ppm})$. In simulation esmFixClim1, only the vegetation module experiences the increase in $\mathrm{CO}_{2}$, while the atmosphere continuously experiences preindustrial $\mathrm{CO}_{2}$ levels. Conversely, in simulation esmFdbk1, only the atmosphere experiences the increase in $\mathrm{CO}_{2}$, while vegetation continuously experiences preindustrial $\mathrm{CO}_{2}$ levels. The simulation esmFixClim 1 thus isolates the impact of $\mathrm{CO}_{2}$ increase on climate through the physiological effect of $\mathrm{CO}_{2}$ on vegetation (which affects land-atmosphere fluxes and thus feeds back on the atmosphere), while esmFdbk1 isolates the radiative effect only of $\mathrm{CO}_{2}$ increase on climate. We thus hereafter refer to simulations 1pctCO2, esmFixClim1, and esmFdbk1 as CTL, PHYS, and RAD, respectively. These simulations and the corresponding decomposition of $\mathrm{CO}_{2}$ effects into physiological and radiative parts in CMIP5 models have been used in previous studies (e.g., Swann et al. 2016; Lemordant et al. 2018), although ET partitioning specifically has not been investigated. For each run we analyze the first 20 years and the last 20 years of the simulations to obtain the corresponding changes (note that $\mathrm{CO}_{2}$ concentrations in the RCP8.5 scenario reach around $935 \mathrm{ppm}$ by the year 2100). Only six models took part in these experiments and provided all the outputs necessary for our analysis (including ET partitioning): BCC-CSM1.1, CanESM2, CESM1(BGC), GFDL-ESM2M, IPSL-CM5A-LR, and NorESM1-ME.

Finally, for all simulations, all model output is regridded to a common $2^{\circ} \times 2^{\circ}$ grid before analysis.

\section{Results}

\section{a. Mean ET partitioning in CMIP5 models}

Figure 1 shows the mean annual surface evaporation in CMIP5 models and its partitioning into transpiration, soil evaporation, and canopy interception. Reflecting the overall zonal pattern of wet and dry regions, land ET (Fig. 1a) is highest in equatorial regions (where it can be locally higher than over oceans; not shown) and lowest in dry subtropical regions, and in some regions like Eurasia it reaches a secondary maximum at middle to high latitudes. The overall pattern of ET partitioning largely reflects the role of vegetation in favoring one 

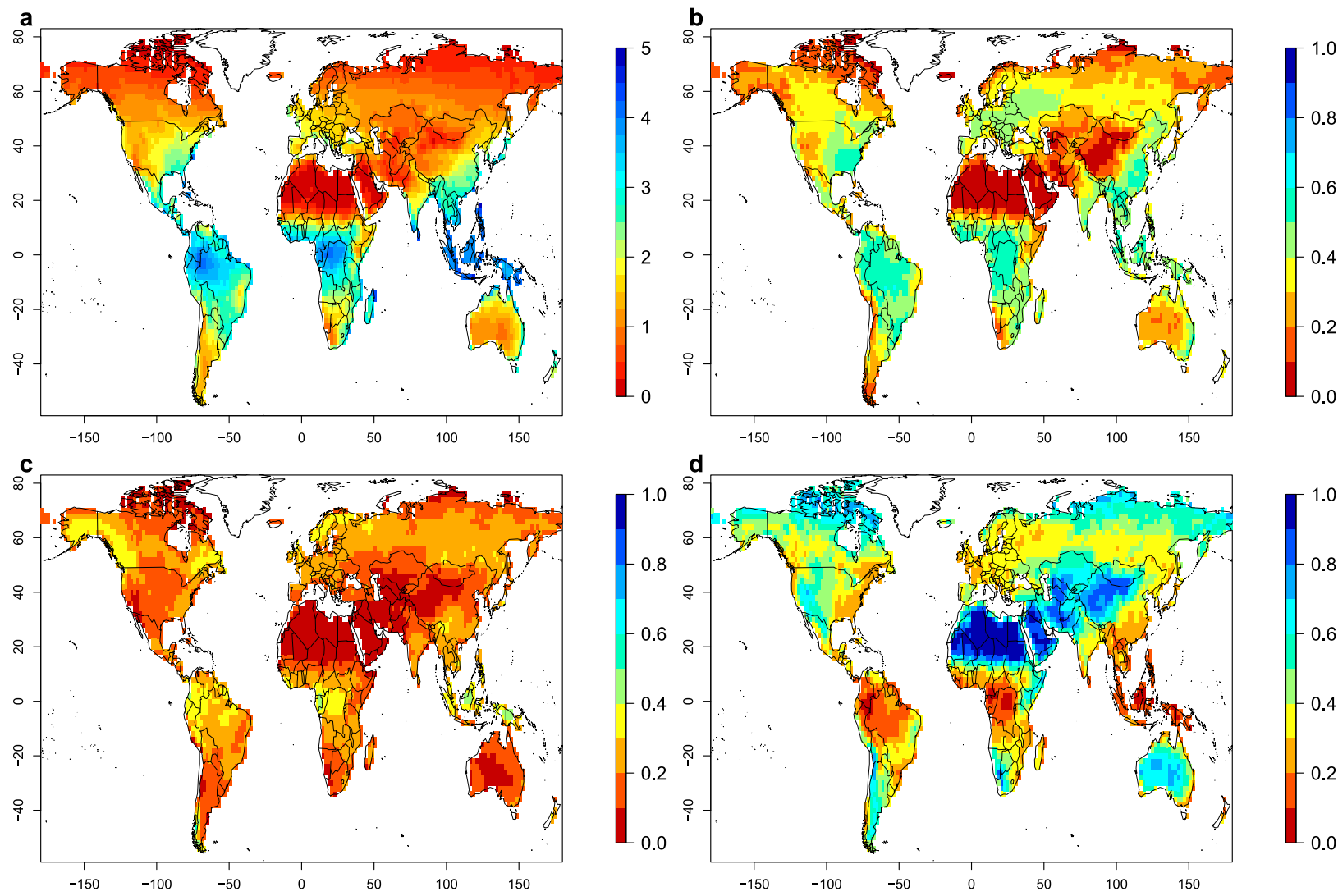

FIG. 1. Multimodel mean annual mean values over 1950-2005 of (a) ET (mm day ${ }^{-1}$ ) and fractions of (b) transpiration, (c) canopy interception, and (d) soil evaporation in total ET. A total of 32 models with full ET partitioning are used.

pathway of evaporation over another. The dominant term is transpiration (Fig. 1b), reaching $40 \%-60 \%$ of ET in the tropics, in many parts of the midlatitudes, and in Southeast Asia. This primarily corresponds to the distribution of vegetation around the globe (Fig. 2a): more vegetation leads to more of total ET to occur as transpiration. However, as vegetation gets denser (higher LAI), the fraction of transpiration tends to saturate in the models (Fig. 2b). For instance, in the tropics, where vegetation is the densest, the share of transpiration is not much greater than in the midlatitudes. This is because canopy interception starts to play a significant role as LAI increases (Fig. 2c): precipitation rates and high LAI values are typically the two drivers of canopy interception parameterization in climate models (e.g., Lawrence et al. 2007). In the tropics, with high rainfall and high LAI, canopy interception amounts to $30 \%-40 \%$ of total ET (Fig. 1c). Canopy interception also represent a large fraction of ET in some high-latitude regions like Alaska/western Canada or Scandinavia, even though total LAI is lower than in the tropics. We speculate that this is because these are climatic regions where rainfall is dominated by long-duration synoptic events, where low-intensity rainfall favors continuous wetting of the canopy, as opposed to tropical regions where rainfall is dominated by shorter-duration, convective events with higher rainfall rates that may be less conducive to canopy interception (Miralles et al. 2010). Overall, while the fraction of transpiration tends to saturate as a function of LAI, the fraction of canopy interception increases more linearly. We note that, since canopy interception parameterizations are typically not linear functions of LAI (e.g., Lawrence et al. 2007), this apparent linearity may emerge as a result from combined regional variations in, for example, LAI and precipitation characteristics.

Finally, soil evaporation is the dominant term in dry subtropical regions with little vegetation, such as Australia, southern Africa, or western North America, reaching up to $60 \%$ of total ET, and up to $100 \%$ in desert regions like the Sahara and the Middle East (Fig. 1d). In these regions total ET is low (Fig. 1a). The fraction of soil evaporation decreases rapidly in models as LAI initially increases (Fig. 2d) but still represents around $10 \%$ of ET in the tropics, and between $20 \%$ and $40 \%$ in 

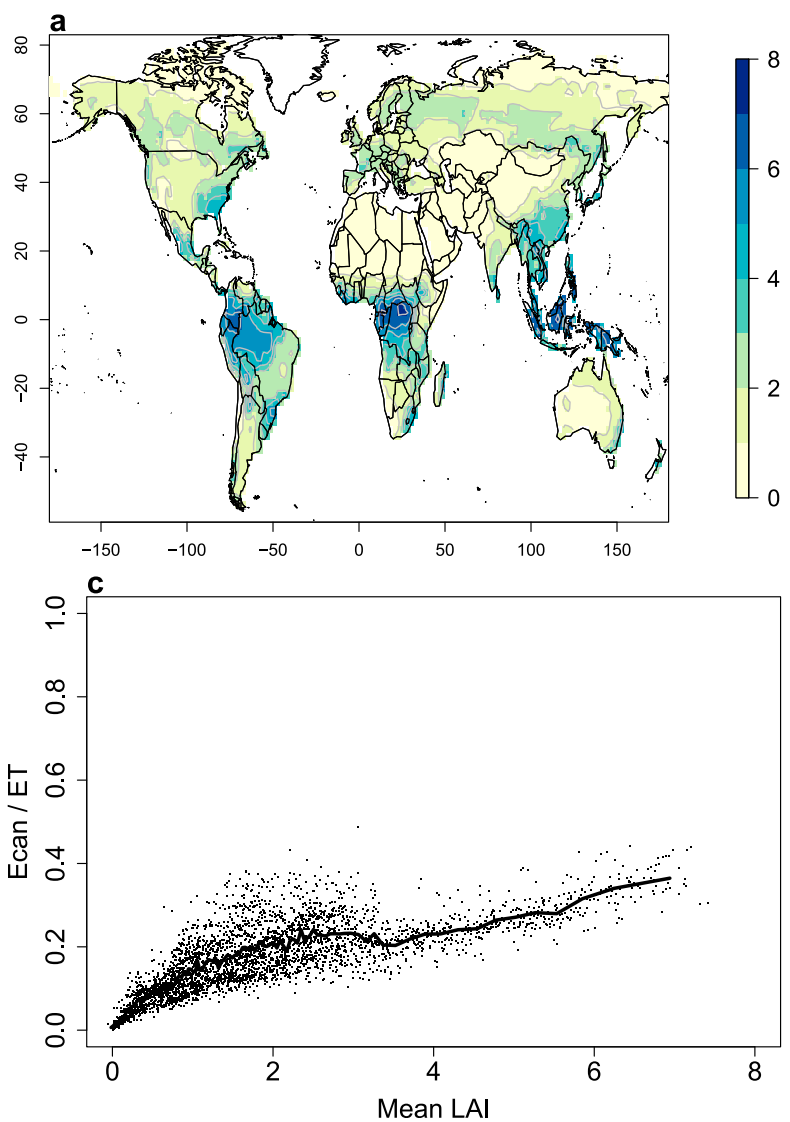
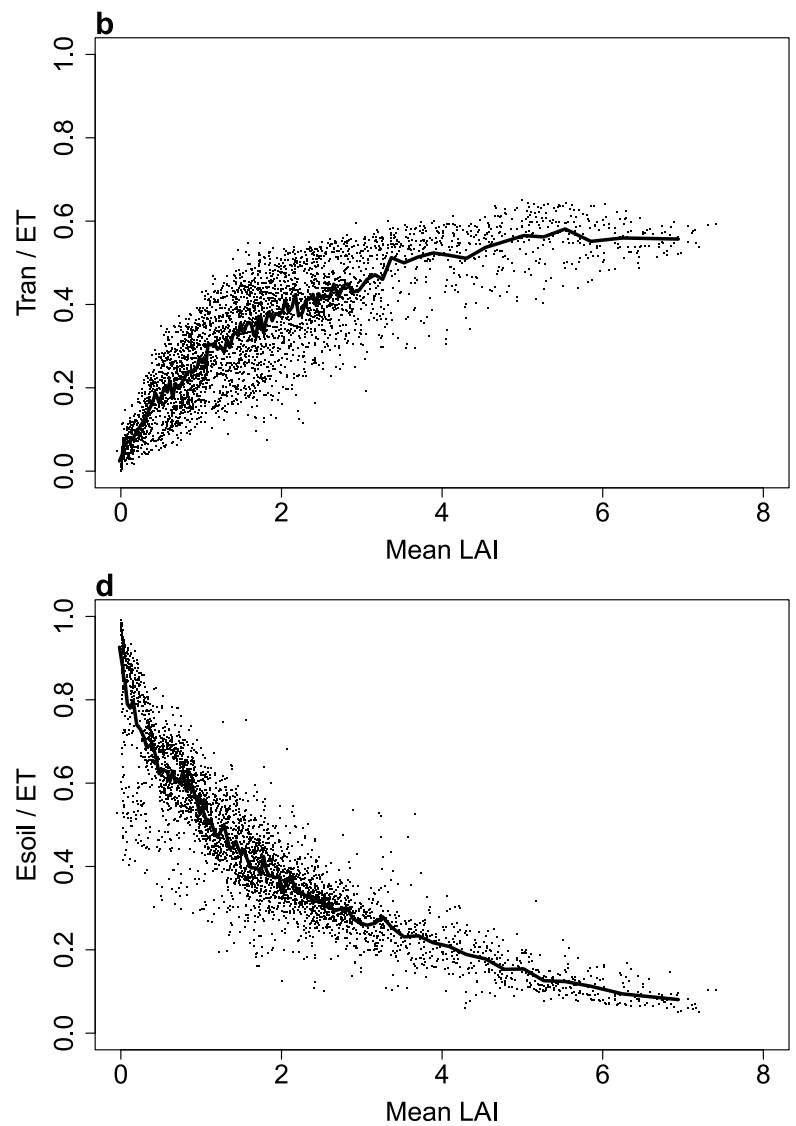

FIG. 2. (a) Multimodel mean annual LAI over 1950-2005. Also shown are the relationships between the multimodel mean LAI and the multimodel mean fraction of (b) transpiration (Tran), (c) canopy interception (Ecan), and (d) soil evaporation (Esoil). Each dot corresponds to a land pixel. The full line is a binned average. Multimodel means are calculated for the 22 common models for which all three components of ET and LAI were available.

many midlatitude regions, as well as monsoon regions like India and the Sahel.

\section{b. Model spread in ET partitioning in CMIP5 models}

CMIP5 models generally share the same first-order spatial patterns of ET partitioning. However, there is a large spread in amplitude across models. Figure 3 shows the mean partitioning averaged over the whole land surface and the distribution across CMIP5 models. Transpiration is the dominant term, accounting for $42 \%$ of total ET. Soil evaporation comes in second, with a mean value $35 \%$, and canopy interception is third, with a mean value of $22 \%$. However, the fraction of transpiration, for instance, extends from nearly $15 \%-60 \%$. The fraction of soil evaporation extends from $13 \%$ to $63 \%$. Model differences extend to the very rank of the three components: while most models agree on the order of terms as shown in Fig. 3, in some models soil evaporation is the leading term, whereas in other it comes last, after canopy interception, and in some models transpiration is the smallest term (Fig. S1). We discuss the realism of these different ET partitioning values in the discussion section.

Figure 4 shows the spatial pattern of how the model spreads in the different ET components relate to each other, displaying cross-model correlations between the different terms. Generally, the transpiration and soil evaporation fractions are strongly negatively correlated everywhere (Fig. 4a): models with a greater transpiration fraction tend to have a smaller soil evaporation fraction. In many regions of the tropics and midlatitudes, higher transpiration fractions also come at the expense of canopy interception (Fig. 4b). However, in dry subtropical regions, as well as dry midlatitude regions and at high latitudes, the fractions of transpiration and canopy interception are positively correlated, both then being negatively correlated with the fraction of soil evaporation (Fig. 4c).

Figure 5 shows that these intermodel differences can, to some extent, be linked to differences in the model representation of vegetation. The large majority of 


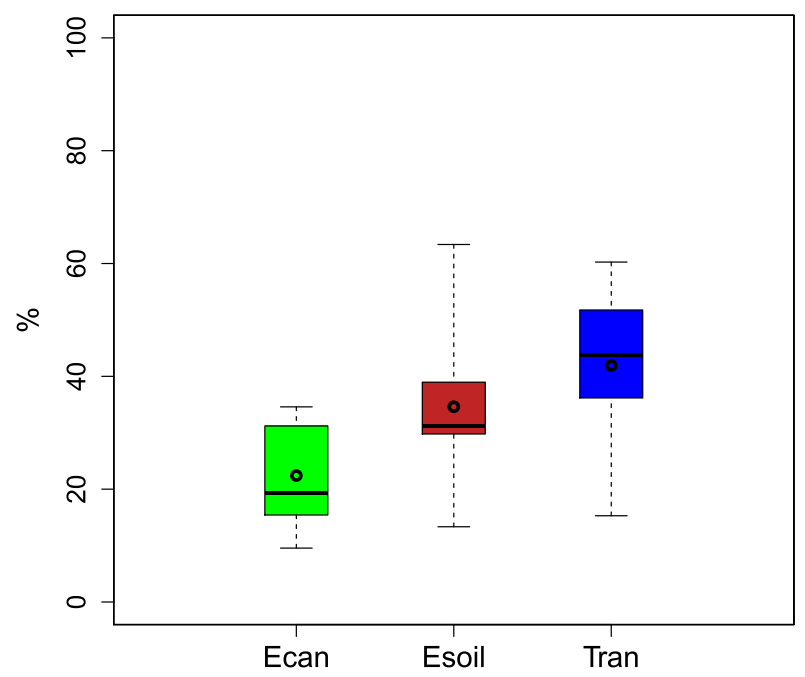

FIG. 3. Mean value and spread across CMIP5 models of the global fraction of each ET component (\% of total ET). Ecan: canopy interception; Esoil: soil evaporation; Tran: transpiration; 32 models with full ET partitioning are used. The thick line represents the median of the distribution, the central dot the mean, and the edges of the box the $25 \%$ and $75 \%$ quantiles. Whiskers represent the total model range.

climate models simulate vegetation and LAI interactively with climate, although a few use prescribed LAI (ACCESS1.0 and ACCESS1.3, FIO-ESM, MIROC4h, and MIROC5). Previous studies have found a large range of LAI values across models (e.g., Mahowald et al. 2016). Here global mean model LAI ranges (over the 22 models for which we have both LAI and ET partitioning) from 0.9 to 3.1, with a median of 2.1. Figure S2 shows the model spread is largest, numerically, in regions of higher LAI (e.g., tropics), although when normalized by mean LAI the model spread is actually greatest, in relative terms, in drier areas and in the high latitudes. The fraction of transpiration is generally positively correlated, locally, with the amount of vegetation (LAI) in models (Fig. 5a); so is the fraction of canopy interception (Fig. 5c). The sum of both is thus clearly positively correlated with vegetation (Fig. 5d). In contrast, the fraction of soil evaporation is clearly negatively correlated with LAI across models (Fig. 5b). These relationships are consistent with those established in Fig. 2 for the multimodel mean pattern of partitioning, and likely stem from similar processes: higher LAI favors transpiration and canopy interception at the expense of soil evaporation. Thus, not only does simulated vegetation explain the mean pattern of simulated ET partitioning, it also affects intermodel differences in partitioning. The role of vegetation also explains the patterns seen in Fig. 4: since vegetation is a main determinant (positively) of the transpiration fraction and (negatively) of the soil evaporation fraction, both fractions are necessarily anticorrelated across models (Fig. 4a); in addition, in dry regions where mean LAI is low, both the transpiration and canopy interception fractions increase with higher LAI (presumably associated with increased precipitation as well) and are thus positively correlated across models (Fig. 4b).

\section{c. Relationship between ET partitioning and surface climate in CMIP5 models}

Does the way CMIP5 models simulate ET partitioning influence the characteristics of their simulated surface climate? Indeed, transpiration, soil evaporation, and canopy interception respond differently to atmospheric variability, with potential implications for feedbacks from the surface to the atmosphere. Typically, the time scale of the evaporation response to a rain event can be expected to decrease from transpiration to soil evaporation and canopy interception: the superficial canopy water store is depleted most quickly, followed by soil evaporation (which mostly draws water from the first top centimeters of the soil) and transpiration, since plants have access to deeper and larger soil water storage. Mean ET properties can thus be affected by how ET partitioning is simulated, with attendant feedbacks on surface climate. Lawrence et al. (2007) and Williams et al. (2016) report changes in land-atmosphere coupling and surface climate characteristics (e.g., changes in the frequency distribution of precipitation) when deliberately altering ET partitioning in their model. Similar effects might thus be at play across the CMIP5 ensemble of models, with differences in ET partitioning feeding back on characteristics of surface climate. Here we explore these effects, investigating first potential differences in summertime temperature, as this is the variable most likely to be affected by land-atmosphere processes (e.g., Berg et al. 2014).

Exploring potential climate differences induced by differences in ET partitioning between models is made challenging by the compounding effect of model differences in surface climate and surface fluxes that exist independently of ET partitioning. In particular, any feedback from ET partitioning on surface climate may be compounded by concurrent differences in total ET. Figure 6a shows that, indeed, summertime ET partitioning is partly correlated across models with mean ET (in summer): models that simulate greater ET tend to also be the ones showing greater fractions of transpiration in some parts of the subtropics and midlatitudes, with correspondingly smaller fractions of soil evaporation. We interpret these relationships as mostly reflecting the impact of differences in precipitation in driving simultaneous and mutually reinforcing differences in 

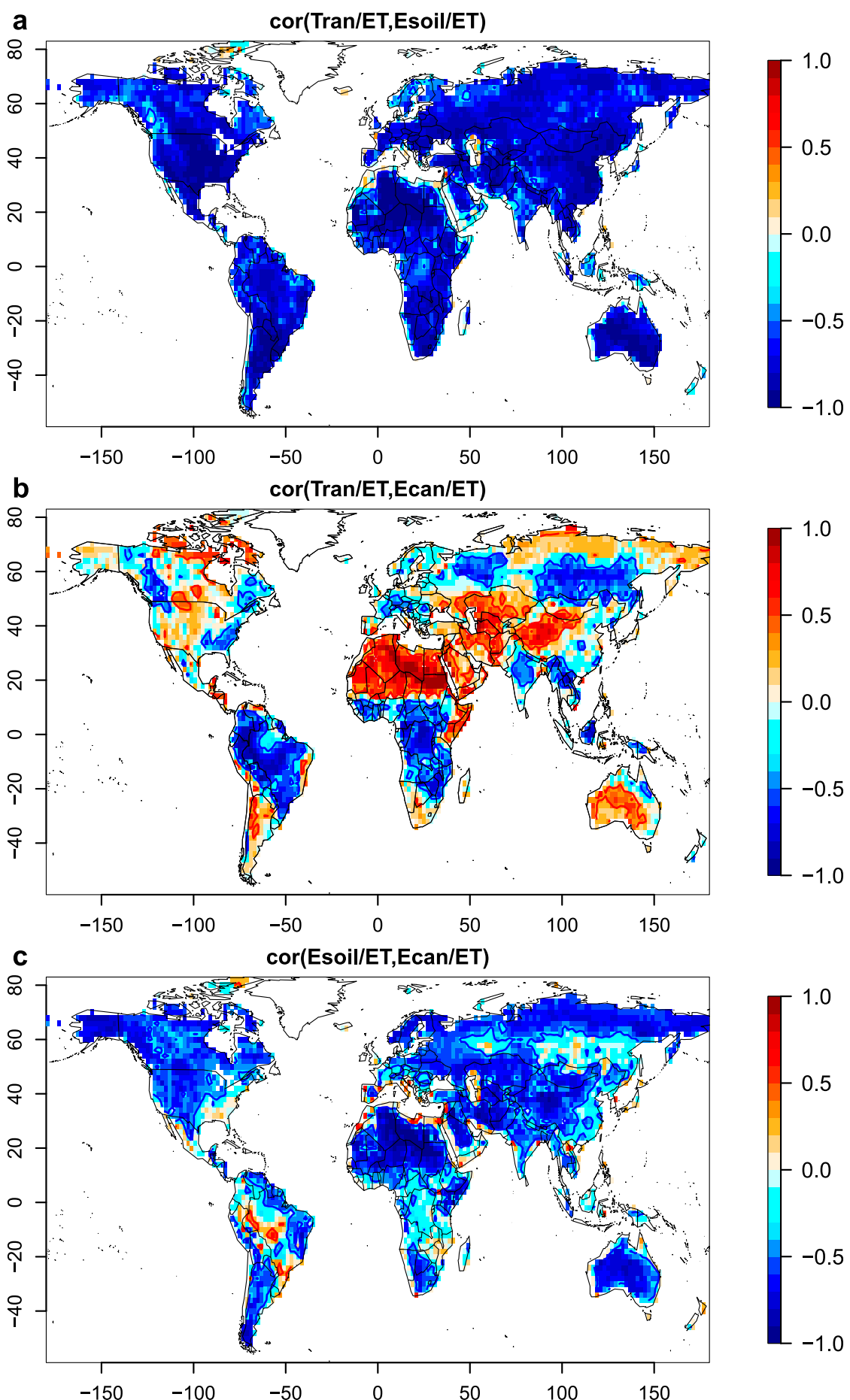

FIG. 4. Cross-model correlation of the mean annual fractions of (a) transpiration and soil evaporation, (b) transpiration and canopy interception, and (c) soil evaporation and canopy interception; 32 models with full ET partitioning are used. Red and blue contour lines indicate positive and negative correlations, respectively, that are significant at the $5 \%$ level. 

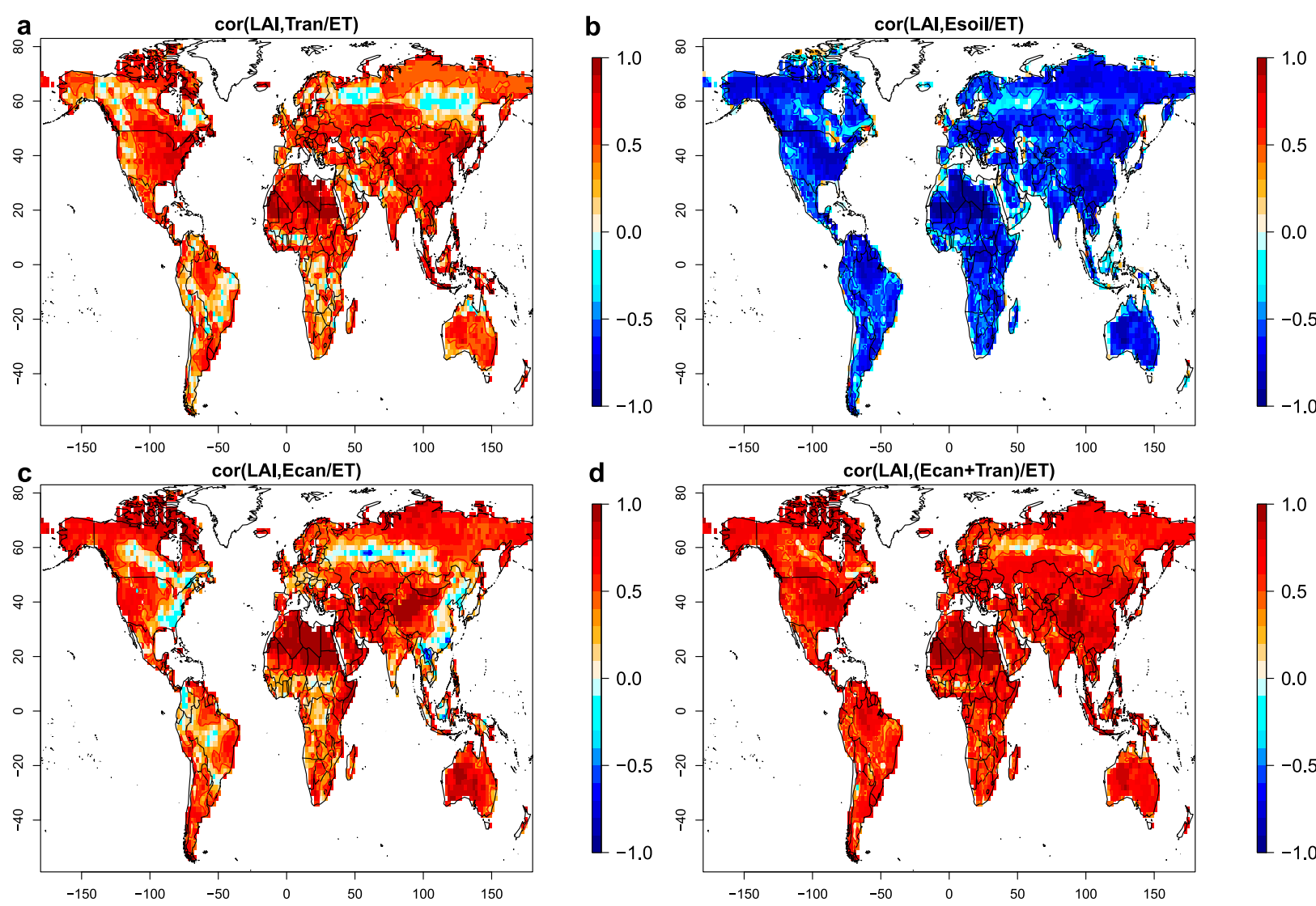

FIG. 5. Cross-model correlation of mean LAI and (a) transpiration fraction, (b) soil evaporation fraction, and (c) canopy interception fraction, and (d) the sum of the canopy interception and transpiration fractions; 22 common models with available LAI and ET partitioning outputs were used. Red and blue contour lines indicate positive and negative correlations, respectively, that are significant at the $5 \%$ level.

vegetation, transpiration, and overall ET. For instance, wetter models may simulate more vegetation, thus increasing the transpiration fraction; since plants access greater soil water stores, greater transpiration may also help to sustain even higher ET, in particular throughout the summer. On the other hand, model differences in ET lead to differences in near-surface temperature across models (as greater evaporative cooling cools the surface; Fig. S3). Thus, cross-model correlations between nearsurface climate and ET partitioning may emerge that are primarily due to model differences in precipitation and ET, rather than independent differences in ET partitioning. We subsequently try to control for this effect when investigating the relationship between ET partitioning and other variables, by using partial correlations controlling for model differences in ET.

Figure $6 \mathrm{~b}$ shows the partial correlation between ET partitioning and mean summertime 2-m temperature across CMIP5 models, controlling for differences in mean (summertime) ET. The partial correlation is the correlation between the residuals from two regressions between, on the one hand, model ET and ET partitioning (whose correlation is shown on Fig. 6a) and, on the other hand, mean ET and mean temperature (correlation shown in Fig. S3). It thus isolates the relationship between model differences in ET partitioning and temperature after removing the influence of model differences in mean ET. Figure 6b shows that over many regions, greater transpiration fractions and lower soil evaporation fractions are associated with lower mean summertime temperature. This is particularly the case for soil evaporation fractions over southern Africa, South and North America, and many parts of Asia. Because we control for differences in mean ET between models, we interpret this correlation as primarily reflecting a feedback from ET partitioning on near-surface air temperature. We note that if we did not control for ET, patterns of the correlation between 2-m temperature and, for instance, the transpiration fraction would look significantly different, mostly reflecting both the relationships across models between ET and temperature and between ET and transpiration fraction (Fig. S4). 


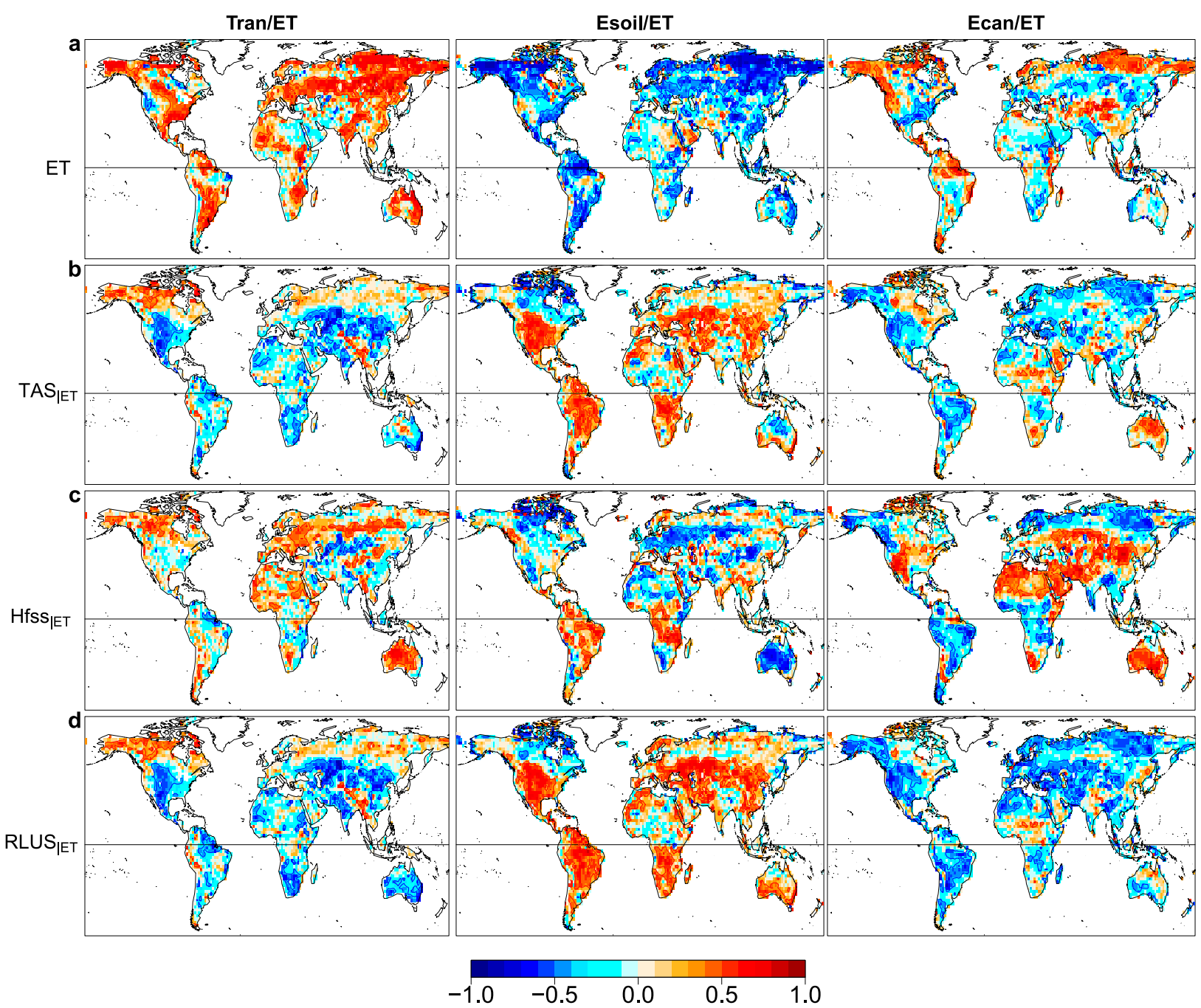

FIG. 6. (a) Cross-model correlation between summertime-mean ET and ET component fractions (columns). Also shown are crossmodel partial correlations between summertime-mean ET component fractions and (b) 2-m temperature (Tas), (c) surface sensible heat flux (Hfss), and (d) surface upwelling longwave radiation (RLUS), controlling in each case for mean summertime ET (as indicated by the subscript in the left hand-side labels; see text for details). Summertime is defined as JJA in the Northern Hemisphere and DJF in the Southern Hemisphere, with means taken over 1950-2005. A total of 29 common models for which all variables were available are used for all correlations. Red and blue contour lines indicate positive and negative correlations, respectively, that are significant at the $5 \%$ level.

When considering simple cross-model correlations, lower transpiration and greater soil evaporation fractions are generally associated, as expected, with higher sensible heat flux (consistent with reduced ET; Fig. S4). However, when controlling for model differences in mean ET, the correlation pattern is more complex, with both reduced and increased sensible flux values (Fig. 6c). In particular, the partial correlation of soil evaporation fractions with sensible heat flux values (controlling for ET) is nil or negative in the midlatitudes. This means that for a given level of ET, models that have greater soil evaporation fractions actually show reduced sensible heat flux values. This lack of overlap with Fig. $6 b$ suggests that the relationship between soil evaporation and transpiration fractions and 2-m temperature in Fig. $6 \mathrm{~b}$ is not simply explained by associated model differences in sensible flux, except to some extent in the tropics. Rather, the overlap between Figs. $6 \mathrm{~b}$ and $6 \mathrm{~d}$-which shows the partial correlation between ET partitioning and upwelling surface longwave radiationsuggests that part of the relationship between ET partitioning and 2-m temperature (Fig. 6b) stems from the effect of differences in emission of longwave radiation. In other words, for a given level of ET, greater soil evaporation fractions, for instance, lead to greater near-surface air temperature also because they are associated with a 

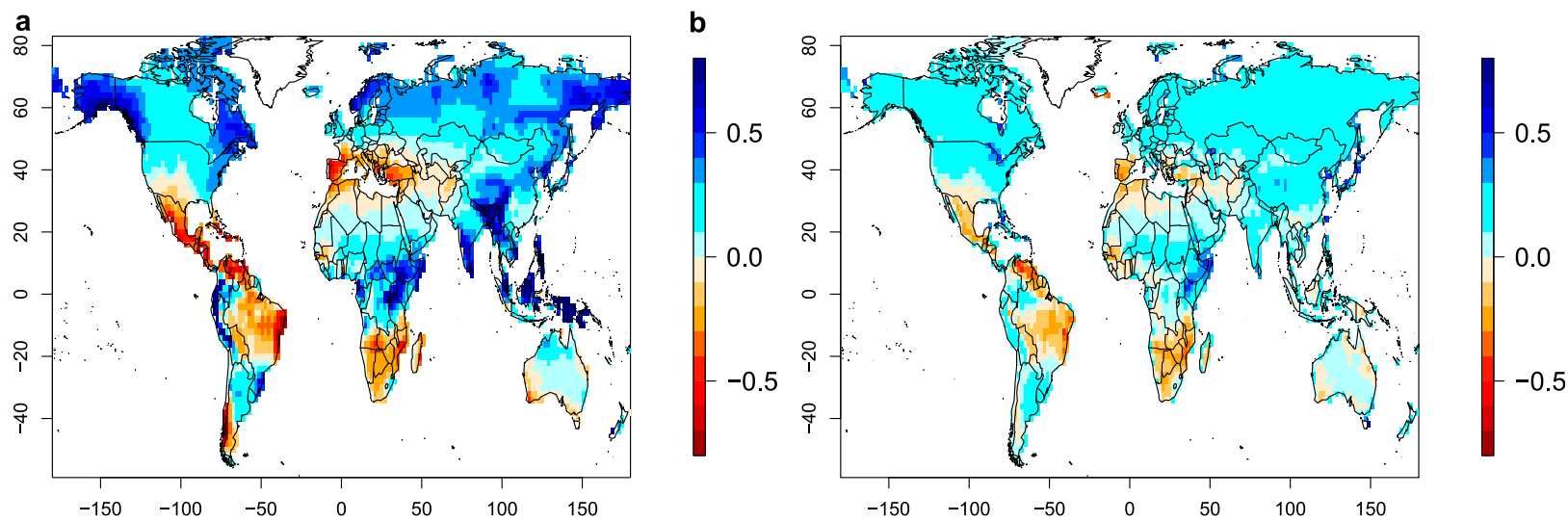

FIG. 7. Multimodel mean change $\left(\mathrm{mm} \mathrm{day}^{-1}\right)$ in (a) annual mean precipitation and (b) annual mean ET, defined as 2071-2100 minus 1950-2005. For consistency with Fig. 8, 24 models with full ET partitioning outputs for RCP8.5 were used. For readability, colors saturate beyond the color scale range on (a).

greater share of the incoming surface energy being reemitted as longwave radiation, thus with higher surface temperatures and higher near-surface temperatures (no such relationship was found between ET partitioning and net shortwave radiation or albedo; not shown).

Overall, Fig. 6 shows that, beyond the feedback of differences in mean model ET on surface climate (Fig. S3), differences in how a given level of ET is partitioned are also associated with differences in landatmosphere fluxes and thus in mean surface climate across CMIP5 models, with the most plausible interpretation being that differences in partitioning, mostly related to differences in vegetation (section $3 b$ ), feed back on surface climate.

\section{d. Future changes in ET partitioning in CMIP5 models}

Figure 7 shows multimodel mean projected changes in ET and precipitation (using a subset of models for which outputs of future ET partitioning are available). Changes in precipitation have been largely documented and analyzed elsewhere (e.g., Scheff and Frierson 2012), with decreases in the dry subtropics and some parts of the tropics (e.g., Central and South America), and increases at middle to high latitudes. Here, we simply note that there is, to leading order, a qualitative correspondence between changes in precipitation and ET, with similar-sign changes in ET as in precipitation. We also note that changes in ET in regions of negative precipitation change tend to be of smaller magnitude than precipitation changes, implying a negative change in runoff. Here we investigate how changes in ET are realized in terms of ET partitioning.

While there is a large spread between models in the simulation of the present-day mean ET partitioning (section 3b), Fig. 8 shows that CMIP5 models project robust future changes in partitioning, with more than three-quarters of the models agreeing on the sign of changes in most regions. In the middle and high latitudes, as well as over the Tibetan Plateau, all three components of ET increase in absolute value (Figs. 8a-c). However, transpiration increases more than soil evaporation, so that the fraction of transpiration increases while the fraction of soil evaporation decreases over most of these regions (Figs. 8d-f). Exceptions to this pattern include parts of Europe, northeast China, and the eastern United States, where it is the fraction of soil evaporation that increases (although transpiration still increases in absolute terms). Absolute increases in all three components are consistent with increases in precipitation in these regions. This precipitation-driven behavior also explains changes in dry tropical regions where precipitation increases, such as the Sahel and eastern Africa. Similarly, some dry subtropical regions, such as the Mediterranean basin, the southwestern United States, and southern Africa, see simultaneous decreases in all three terms, reflecting decreases in projected precipitation. In these regions transpiration typically decreases more, so that the fraction of soil evaporation actually increases.

In contrast, large parts of the humid tropics show opposite absolute changes in ET components, with concomitant absolute decreases in transpiration (Fig. 8a) but increases in soil evaporation (Fig. 8b) (changes in canopy interception being more muted). As a result the fraction of transpiration decreases (Fig. 8d), and the fraction of soil evaporation increases (Fig. 8e). This is the case in the Amazon, tropical West Africa and central Africa, the Maritime Continent, and Southeast Asia.

Globally, Fig. 9a shows that soil evaporation and canopy interception increase on average (in absolute 

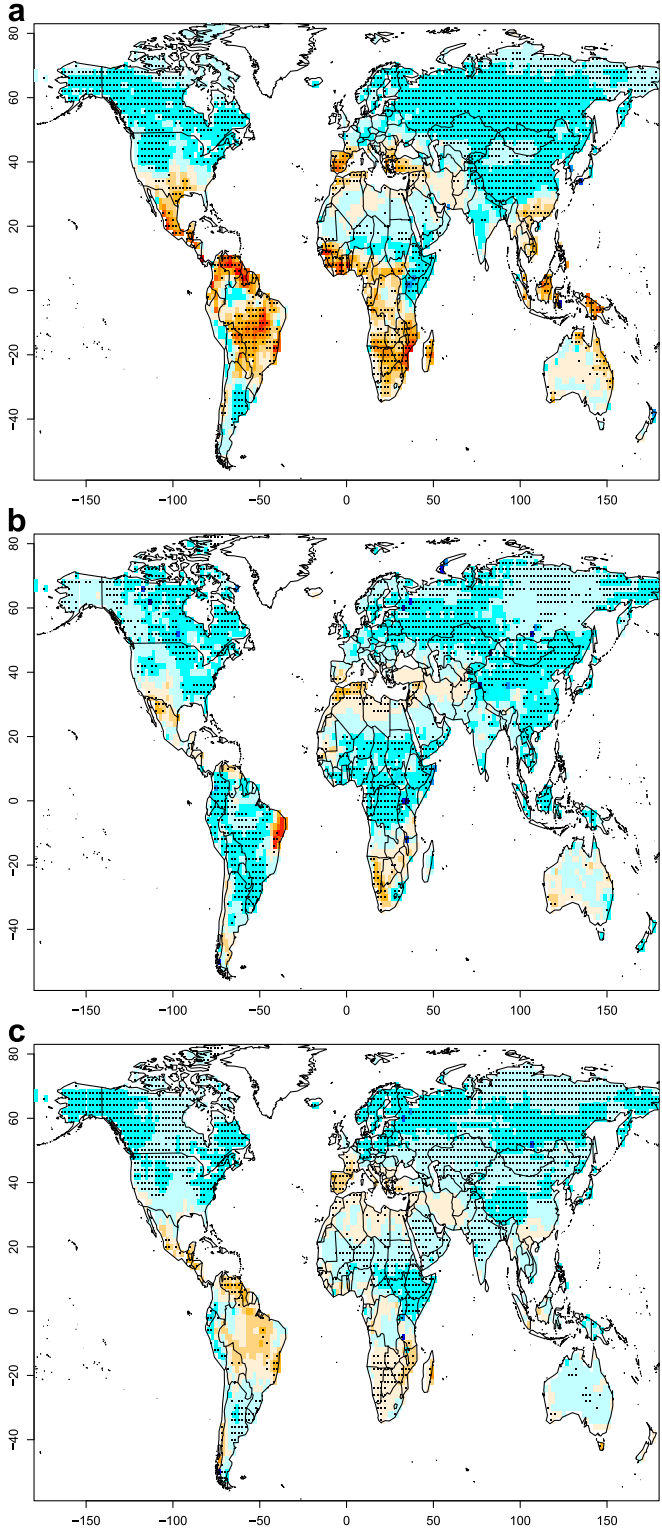
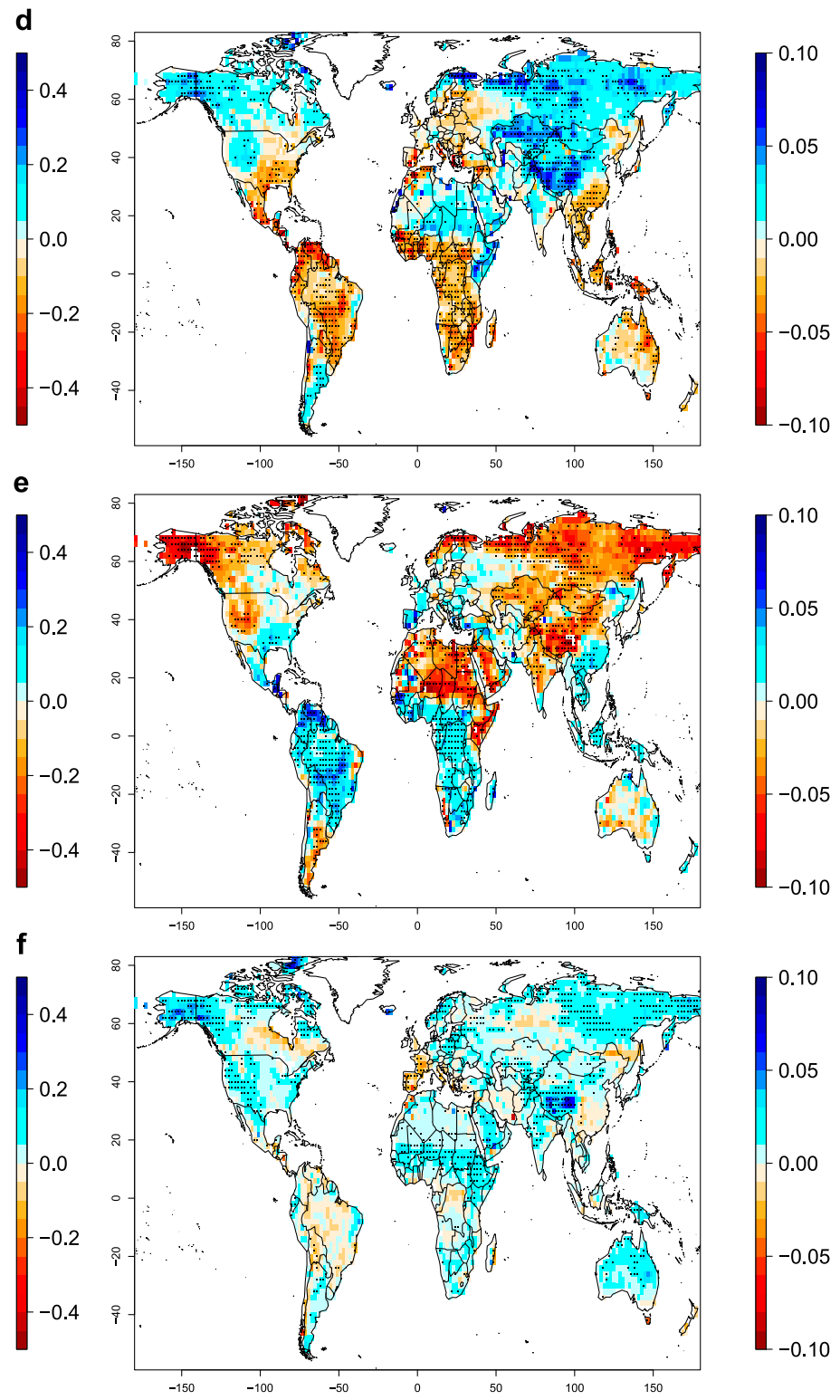

FIG. 8. Multimodel mean change $\left(\mathrm{mm} \mathrm{day}^{-1}\right)$ between 1950-2005 and 2071-2100 in (a) transpiration, (b) soil evaporation, and (c) canopy interception $\left(\mathrm{mm} \mathrm{day}^{-1}\right)$. (d)-(f) As in (a)-(c), but as a fraction of ET. Stippling indicates where more than $80 \%$ of models agree on the sign of changes. A total of 24 models with full ET partitioning in present and future were used to compute changes.

values), with soil evaporation increasing the most; the mean change in transpiration, however, is close to zero, with the largest intermodel uncertainty as quantified by the $25 \%$ and $75 \%$ quantiles. Overall, total ET increases by $0.07 \mathrm{~mm} \mathrm{day}^{-1}$ on average (an increase of around $5 \%$ of the present-day mean of $\left.1.5 \mathrm{~mm} \mathrm{day}^{-1}\right)$. As a result, the fraction of transpiration decreases globally (Fig. 9b). In the tropics specifically, regional averages reflect the behavior described above for global averages: absolute transpiration decreases, which is offset to some extent by increases in soil evaporation. Mean ET does not increase, on average. The fraction of transpiration decreases by a mean of $-2.3 \%$, with only two models showing an increase.

\section{e. $\mathrm{CO}_{2}$ fertilization and future changes in ET partitioning}

Figure 10 shows the spatial patterns of how the model spreads in the projected changes in the different ET components relate to each, with cross-model correlations. Globally, patterns are similar to those for presentday partitioning (Fig. 4): across models, changes in 
a

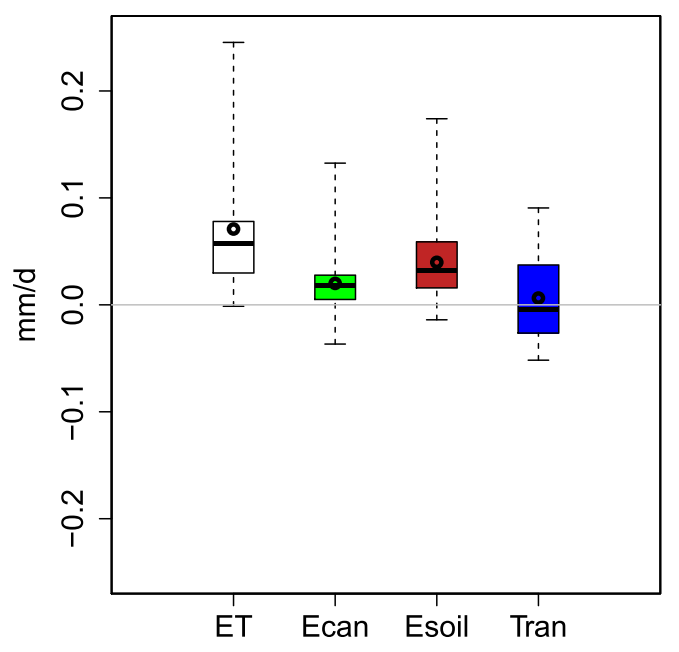

C

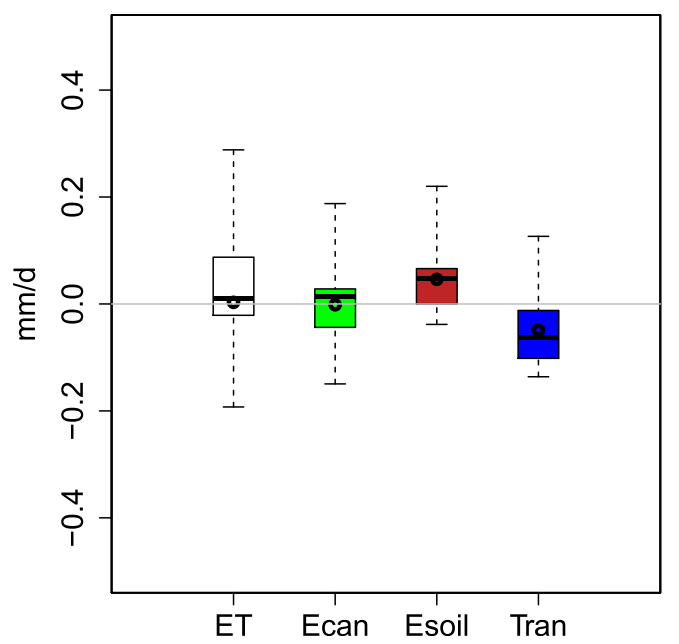

b

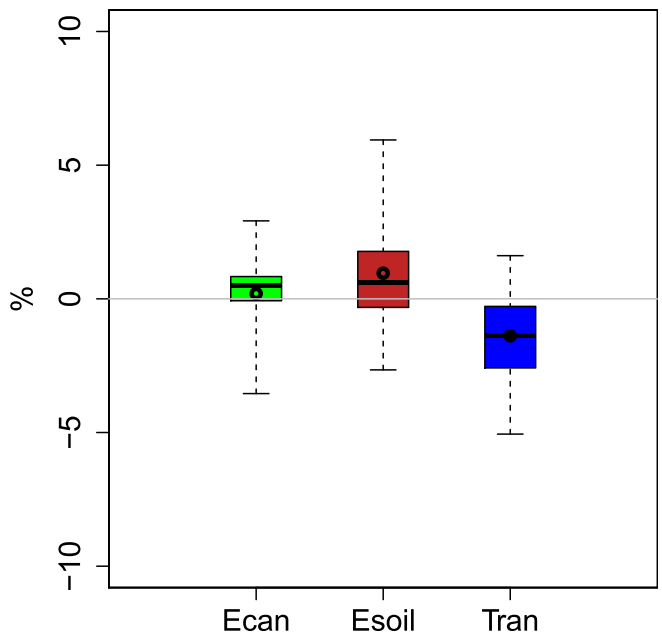

d

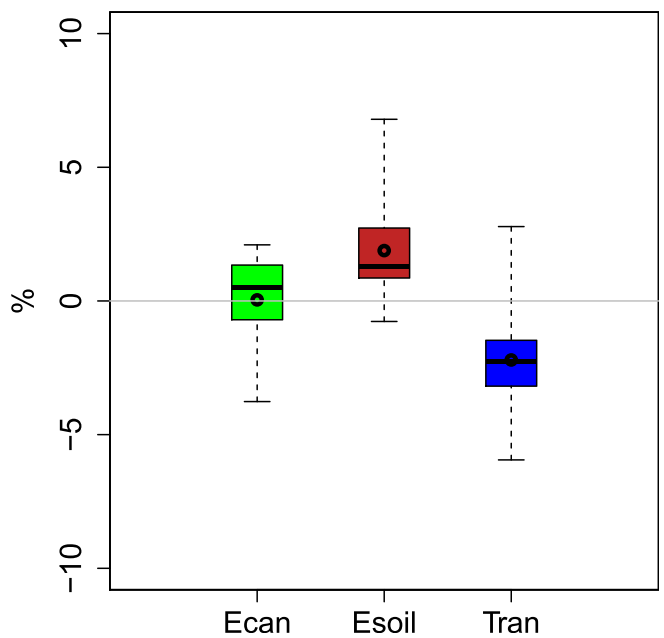

FIG. 9. Multimodel mean changes in annual ET and its components averaged globally over land, (a) in absolute values and (b) as fractions of ET. (c),(d) As in (a) and (b), but over the tropics only $\left(20^{\circ} \mathrm{S}-20^{\circ} \mathrm{N}\right)$. The meaning of the boxplot is the same as in Fig. 3. A total of 24 models with full ET partitioning in the present and future were used to compute the changes.

transpiration fractions and canopy interception fractions go hand in hand in most regions at the expense of changes in soil evaporation fractions, except in the tropics where changes in the fractions of soil evaporation and canopy interception are both negatively correlated with changes in transpiration fraction.

Given the role of vegetation in explaining both the mean pattern and the intermodel differences in ET partitioning, we similarly investigate the correlation across models between changes in LAI and changes in ET partitioning. Figure 11a shows that, overall, LAI increases around the globe in model projections, including in the tropics. This projected increase has been noted before (e.g., Mahowald et al. 2016) and is consistent with the large land carbon sink projected by Earth system models (Friedlingstein et al. 2014). It is also qualitatively consistent with the observed "global greening" trend in remote sensing data over the last decades (Zhu et al. 2016). Globally, the relationship between changes in LAI and changes in ET partitioning is consistent with results from sections $3 \mathrm{a}$ and $3 \mathrm{~b}$, although more muted (Figs. 11b-d): models where LAI increases the most tend to see greater increases in transpiration fraction and fraction of canopy interception, and lower increases in soil evaporation fraction. However, the relationship between changes in LAI and change in the transpiration fraction tends to break down in the tropics. 

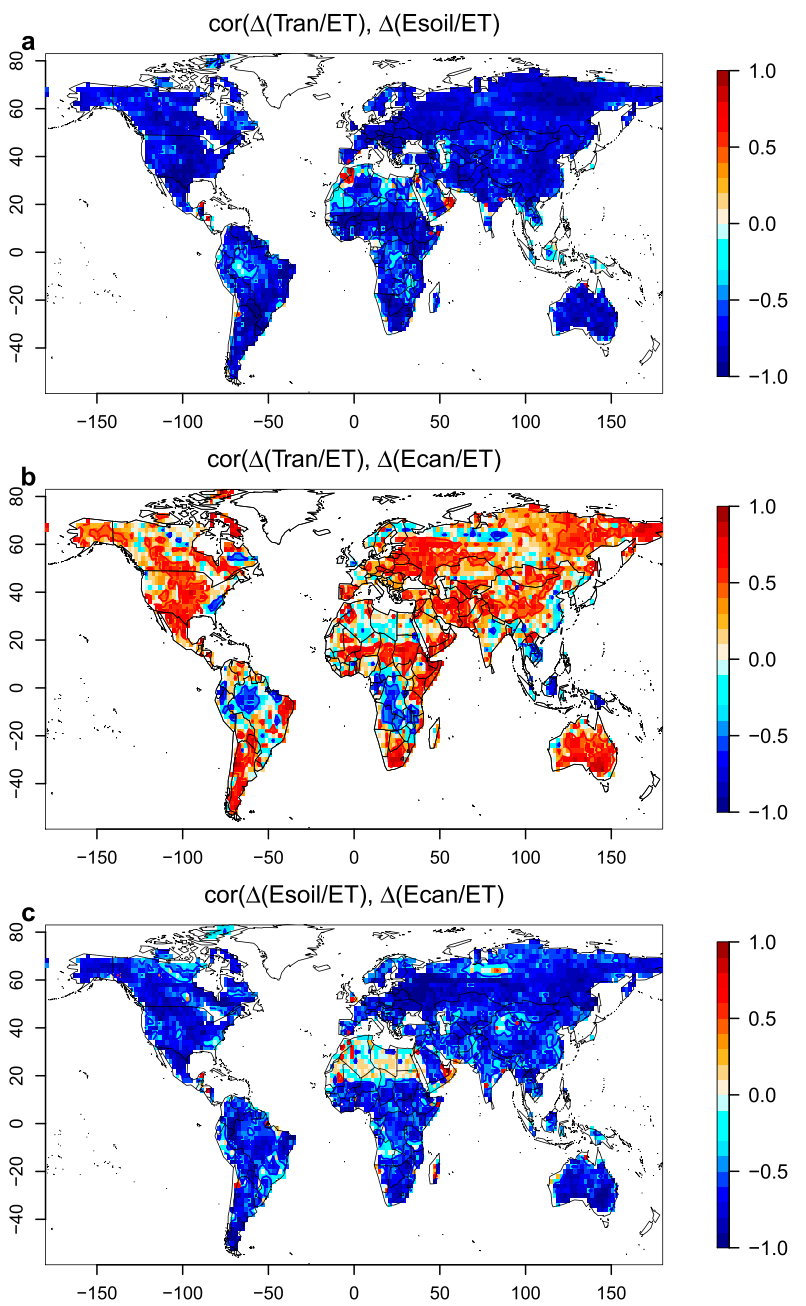

FIG. 10. Cross-model correlations of projected changes (between 1950-2005 and 2071-2100) in the mean annual fractions of (a) transpiration and soil evaporation, (b) transpiration and canopy interception, and (c) soil evaporation and canopy interception. A total of 24 models with full ET partitioning in the present and in the future are used.

The fact that multimodel mean LAI increases in the tropics whereas mean transpiration decreases (both in absolute terms and as a fraction of ET) suggests that the negative impact of increased atmospheric $\mathrm{CO}_{2}$ levels on stomatal conductance (Cowan 1978) compensates the increase in transpiration that could be expected based on increases in LAI. To investigate this hypothesis, we analyze changes in ET partitioning from six models from the CMIP5 experiments CTL, RAD, and PHYS, which allow us to separate the radiative and physiological effects of atmospheric $\mathrm{CO}_{2}$ increase (see section 2). Figure 12 shows that in the six models analyzed, overall changes in precipitation, ET, ET partitioning, and LAI in the CTL simulation are qualitatively consistent with multimodel mean changes from the larger CMIP5 ensemble (Figs. 7, 8, and 11). In particular, despite overall LAI increases, changes in transpiration include a clear decrease throughout the tropics and an increase in soil evaporation, similar to Fig. 8. Figure 12 (third row) shows that this tropical decrease in transpiration is largely due to the physiological effect of $\mathrm{CO}_{2}$. In PHYS, $\mathrm{CO}_{2}$ fertilization largely increases LAI, which could be expected to lead to an increase in transpiration; however, this effect is more than offset by the stomatal closure induced by higher atmospheric $\mathrm{CO}_{2}$ levels (Cowan 1978), so that total transpiration is strongly reduced. (This is reflected in total ET, which decreases as well.) Increases in LAI in PHYS lead to increases in canopy interception, and generally to decreases in soil evaporation, except along the equator where a slight increase in soil evaporation is detectable. However, the increase in soil evaporation in the tropics in CTL appears to be primarily due to the radiative effect of $\mathrm{CO}_{2}$, in particular over central Africa. The radiative effect of $\mathrm{CO}_{2}$ in $\mathrm{RAD}$ is to reduce vegetation in the tropics, presumably from the negative effect on higher temperatures and possibly vapor pressure deficit on photosynthesis in a warm environment. This leads to a shift toward more soil evaporation and less canopy interception. At higher latitudes, in contrast, vegetation increases, and all three components of ET increase, which likely reflect the effect of increased temperature and precipitation from radiatively induced global warming. These increases in all three terms dominate the overall changes in CTL in these regions; indeed, changes in PHYS mostly include only a slight decrease in transpiration.

Finally, we note that, in response to reduced ET, physiologically induced changes in precipitation of both signs occur in PHYS in the tropics, as well a smaller precipitation decreases in the middle to high latitudes. This is consistent with previous studies $(\mathrm{Pu}$ and Dickinson 2014; Skinner et al. 2017) that interpret this pattern as reflecting, in the middle to high latitudes, reduced precipitation recycling, whereas in the tropics reduced ET also leads to changes in circulation and moisture convergence, resulting in a more heterogeneous pattern of precipitation change. In most land regions, however, the overall precipitation signal in CTL appears dominated by changes from RAD. One exception is perhaps over the Amazon, where changes from PHYS appear to contribute largely. This suggests that in Fig. 7, while most of the spatial correspondence between changes in precipitation and ET reflects the impact of the former over the latter, over tropical South America the causal relationship is partly reversed: physiologically induced reductions in transpiration lead to a decrease in 

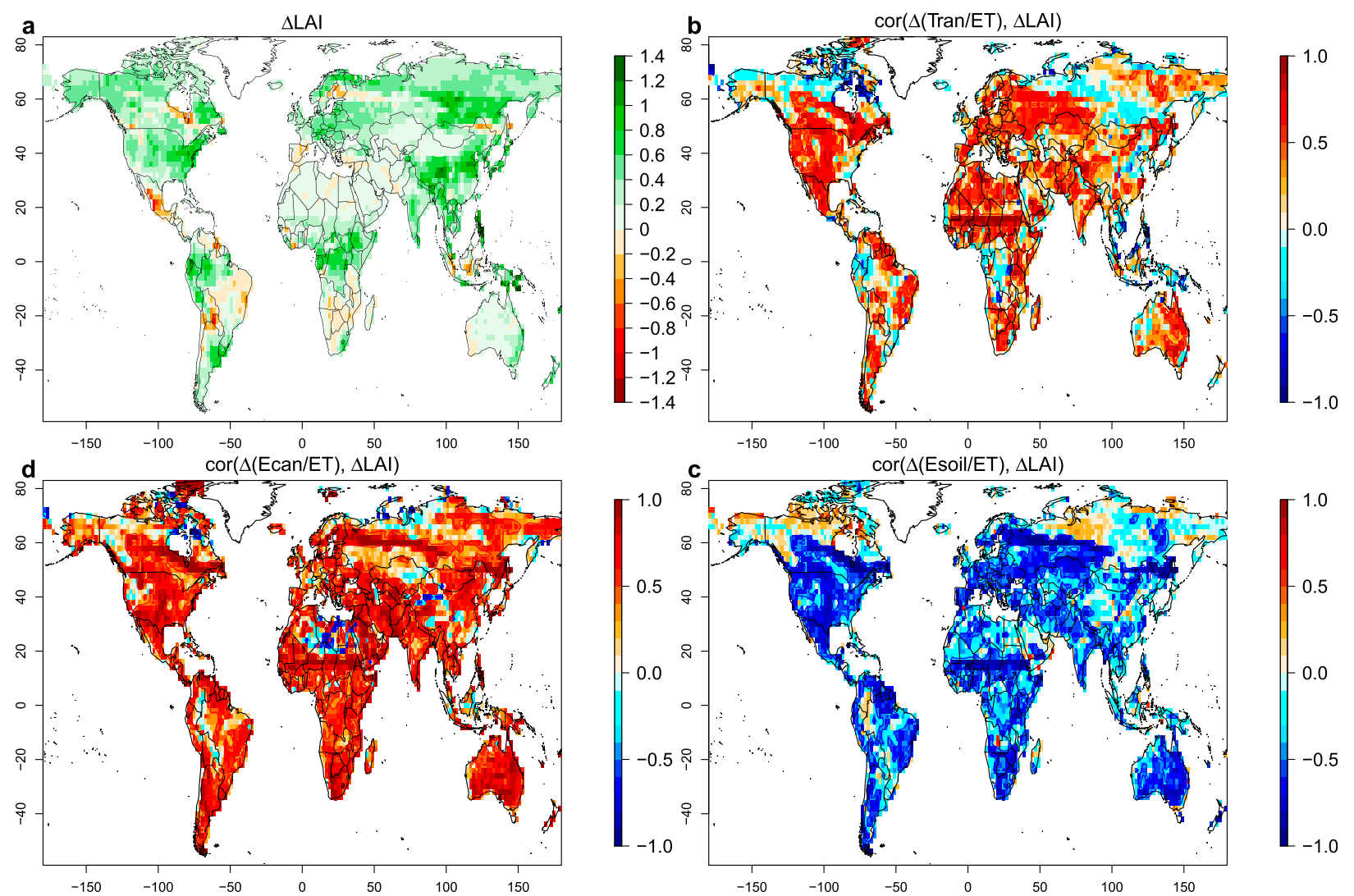

FIG. 11. (a) Multimodel mean projected change between 1950-2005 and 2071-2100 in mean annual LAI, and cross-model correlations of projected changes in LAI and changes in fractions of (b) transpiration, (c) soil evaporation, and (d) canopy interception. A total of 18 common models with available present and future LAI and ET partitioning were used. Red and blue contour lines indicate positive and negative correlations, respectively, that are significant at the $5 \%$ level.

precipitation. This is consistent with similar but singlemodel recent analysis (e.g., Kooperman et al. 2018).

Overall, Fig. 12 confirms that the decrease in transpiration in the tropics in Fig. 7 is primarily caused by the physiological effect of $\mathrm{CO}_{2}$. Model differences in projected changes in the fraction of transpiration thus likely reflect differences in combined changes in LAI and stomatal conductance, and hence there is no clear relationship between changes in LAI alone and transpiration changes in the tropics (Fig. 11b). Because of the physiologically induced transpiration decrease, the change in total ET in the tropics is not as large as it would be based on the radiative effect of $\mathrm{CO}_{2}$ alone. However, Fig. 8 shows that this decrease is offset, to some extent, by radiatively induced increases in soil evaporation, as well as by small increases in canopy interception resulting from the physiologically induced increase in LAI. The total change in ET in the tropics thus comes about as the result of opposite changes in different components of ET partitioning, driven by different physical and biological processes.

\section{Discussion and conclusions}

We have comprehensively investigated how ET partitioning is represented in CMIP5 climate simulations of present and future climate. Large model spread in ET partitioning exists, with the fraction of transpiration, for instance, ranging between $15 \%$ and $60 \%$, and with corresponding differences in other components. Models even show differences in which component dominates ET globally. The mean spatial pattern of ET partitioning can be primarily explained by the effect of vegetation distribution, as was also reported recently in Lian et al. (2018).

Many differences in model parameterization of surface-atmosphere energy and water processes likely contribute to model spread in ET partitioning. Here, we show that not only the multimodel mean, or modelspecific spatial pattern (Lian et al. 2018), but also the model spread in ET partitioning appears strongly linked to model differences in vegetation LAI, with, locally, models with more vegetation exhibiting greater transpiration and canopy interception fractions, and reduced soil 


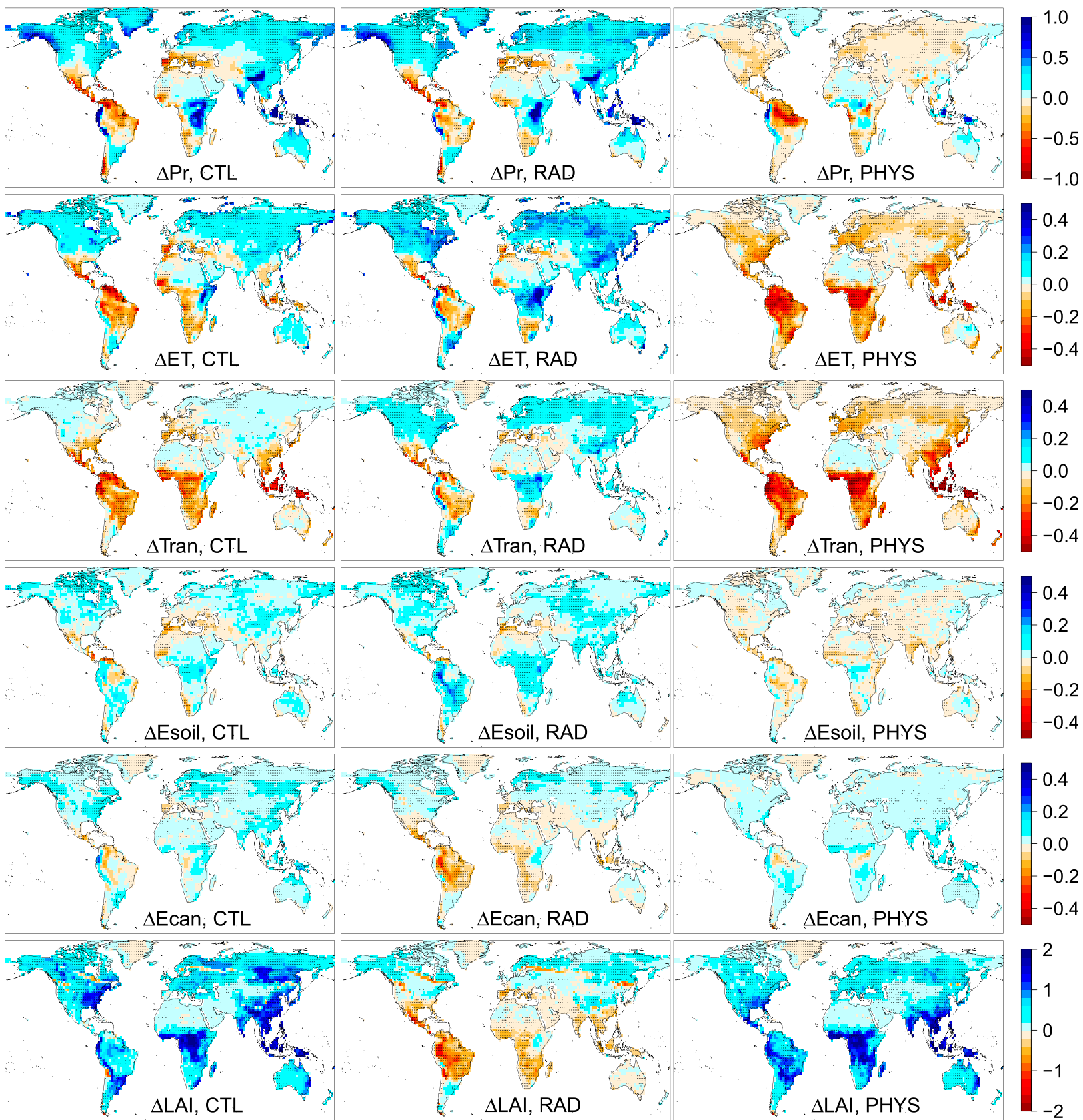

FIG. 12. Multimodel mean changes in (row 1) precipitation, (row 2) ET, (row 3) transpiration, (row 4) soil evaporation, (row 5) canopy interception, and (row 6) LAI in simulations (left) CTL, (center) RAD, and (right) PHYS, between the first and last 30 years of each simulation (see text in section 2). All changes are in $\mathrm{mm} \mathrm{day}^{-1}$ except for LAI, which is unitless. Stippling indicates where 5 out of 6 models agree on the sign of change. For readability, colors saturate outside the range of the color scale.

evaporation. We do not seek here to explicitly investigate why models differ in the representation of LAI. As indicated earlier, some models use prescribed values, although most simulate LAI interactively. Even in the case where LAI is prescribed, different data sources or differences in how different land cover types and land use transitions are implemented, for instance (e.g., de Noblet-Ducoudré et al. 2012), can lead to different LAI values. Among models with prescribed LAI, mean global LAI ranges from 0.9 (MIROC5h) to 1.9 (ACCESS1.0). Among models that simulate vegetation interactively, we find a strong correlation across models between LAI and gross primary production (GPP; not shown), which suggests that model differences in the 
simulation of photosynthesis are partly responsible for model differences in LAI (although the latter can also feed back on GPP).

As mentioned in the introduction, although the components of ET can be measured in different ways at the site scale, ET partitioning is not accurately known at the global or even regional scale. Global remote sensing products of ET, for instance, produce vastly different estimates of ET partitioning (Miralles et al. 2016); while the first-order global spatial patterns of ET partitioning in these products show a general agreement with that in CMIP5 models (Fig. 1), they provide little constraint on the amplitude of the different ET components. However, as mentioned in the introduction, a review of the different estimates of the fraction of transpiration from multiple independent sources-including satellite-based estimations, reanalysis, land surface models, isotopic measurements, and upscaled site measurementsindicates a central mean value around $60 \%$ (e.g., Wei et al. 2017). This suggests that the mean transpiration fraction in CMIP5 models (Fig. 3) is underestimated, as Wei et al. (2017) note. Certainly, values lower than $40 \%$ appear inconsistent with the general understanding of the role of transpiration in global ET (Lawrence et al. 2007). The BCC-CSM1.m, BNU-ESM, CanESM2, and FGOALS models have global transpiration fractions lower than 30\% (Fig. S1). These models are also among those with the highest soil evaporation fractions. The GISS family of models also exhibits low transpiration fractions and the highest fractions of canopy interception. Models with transpiration fractions greater than $50 \%$ include models from the IPSL, NCAR, NorESM, and CNRM families of models. Only the IPSLCM5A-MR model exhibits a transpiration fraction close to $60 \%$.

The positive relationship, across models, between the transpiration fraction and vegetation amount shown on Fig. 5a could suggest, at first glance, that models underestimate mean transpiration fractions because they generally underestimate LAI. However, several studies have evaluated vegetation in climate models and have found, on the contrary, that most models tend to overestimate LAI compared to satellite observations, by up to a factor 2 or more, and that this is true at all latitudes (Anav et al. 2013; Mahowald et al. 2016; Zeng et al. 2016). For instance, models with the highest LAI, here, include the GFDL-ESM2M, GFDL-ESM2G and MRIESM models, with global LAI values between 2.9 and 3.1, while long-term satellite measurements indicate a global mean closer to 1.5 (Anav et al. 2013; Zeng et al. 2016). The overestimation of LAI in climate models has been linked with the general overestimation of GPP also simulated by these models, itself possibly linked to omission of nutrient constraints or of the negative effects of atmospheric ozone (Anav et al. 2013). As indicated above, we do find that GPP and LAI are positively correlated across models, which would support this interpretation. Regardless of what is causing models to overestimate LAI, this overestimation suggest that climate models are not underestimating the role of transpiration simply because they are underestimating vegetation, but rather that they are underestimating the relationship between vegetation cover and transpiration fraction. In other words, for a given amount of vegetation cover, systematic biases in model parameterizations of various land-atmosphere biophysical processes directly influencing ET partitioning lead to an underestimation of transpiration. Lian et al. (2018) recently reached a similar conclusion. Because of the generally positive relationship between LAI and transpiration fraction, forcing the CMIP5 ensemble of climate models with the observed LAI would actually enhance the overall underestimation of the transpiration fraction in these models. For instance, if over each pixel we use a linear relationship between LAI and transpiration fraction derived from Fig. 5a, combined with observed LAI values (from the AVHRR GIMMS LAI3g dataset; Zhu et al. 2013), this yields transpiration fractions that average globally to $37 \%$, compared to an initial multimodel mean of $44 \%$ (over areas where AVHRR GIMMS LAI3g provides data). We also emphasize here that the relationship between LAI and transpiration fraction on Fig. 5a is essentially a local one. Indeed, while most models overestimate LAI globally, they show different spatial patterns: some models simulate proportionally more LAI at high latitudes, for instance. Consequently, the ranking of the different models in terms of how much LAI they simulate is not spatially constant across the globe (not shown). When taking global averages of LAI and transpiration to compute the correlation at the global scale, these spatial differences tend to compensate each other. As a result, this obscures the local relationship between LAI and transpiration fraction (Fig. 5a), and the positive relationship does not hold well at the global scale (i.e., using global averages; $r=0.18$ ). For instance, the model with the largest global LAI, MRI-ESM (global LAI of 3.1), does not have the highest transpiration fraction overall (39\%); IPSL-CM5A-MR exhibits the highest fraction $(60 \%)$ with a global LAI of 1.9. This highlights the importance of analyzing model biases at the regional scale.

By complementarity, the fact that climate models underestimate the fraction of transpiration means that they overestimate the share of soil evaporation and/or canopy interception. Miralles et al. (2010) provide a 
global estimate of canopy interception, which they obtain by driving an analytical model with observations. While, again, the overall pattern of canopy interception in CMIP5 models (Fig. 1) generally agrees, qualitatively, with this estimate, Lian et al. (2018) note that models seem to overestimate the amount of canopy interception globally. Closer examination, here, shows that while models seem to simulate a reasonable ratio of canopy interception to precipitation in the middle and high latitudes, they largely overestimate this ratio in the tropics, with values around $20 \%-25 \%$ (not shown), whereas Miralles et al. (2010) report values closer to $10 \%-15 \%$. These suggest that models may overestimate interception especially in the tropics, which thus potentially explains why they underestimate transpiration at least in those regions. It is worth keeping in mind, however, that Miralles et al. (2010) only derive estimates for tall forests around the world and do not consider shorter vegetation, which might render the comparison with climate models problematic in some regions.

Besides canopy interception, inaccurate representation of canopy light use and root water uptake processes in land models have been suggested to be responsible for the underestimation of transpiration (Lian et al. 2018). Chang et al. (2018) also implicate the role of model deficiencies in (or absence of) the representation of lateral water flow and water vapor diffusion within the soil, while Maxwell and Condon (2016) also point out the necessary role of groundwater flow, generally not accounted for in land models, for sustaining higher transpiration fractions. Further work will likely identify additional sources of land model biases. Some studies have described deliberate efforts to increase the transpiration fraction in land models at the expense of the other components, for instance by modifying formulations and parameters to increase water infiltration and access of vegetation roots to soil water, reduce canopy interception, or increase soil resistance to evaporation (Lawrence et al. 2007; Williams et al. 2016). However, a tension exists between implementing such modifications and potential unintended effects on other aspects of simulated climate or projections (Lawrence et al. 2007). Overall, most current models fail to correctly capture the fundamental role that vegetation exerts on the water cycle through transpiration.

Our analysis further shows that biases in ET partitioning have implications for climate simulations. Differences in ET partitioning across models are associated with differences in land-atmosphere fluxes and surface climate: for a given amount of ET, models that have lower transpiration and more soil evaporation tend to be warmer in summer over large continental regions. Given the systematic underestimation of transpiration by climate models shown here, this also suggests that model biases in ET partitioning may play a role in the well-known warm biases over continents in summer (e.g., Cheruy et al. 2014). Although model differences in (present day) ET partitioning may also influence model spread in future projections of land hydroclimate (e.g., models with less transpiration warming more), our analysis revealed no clear evidence of such a relationship across the CMIP5 ensemble; it may be that the potentially modest impacts of differences in (present day) ET partitioning are masked by the many other model differences affecting climate model projections. Although we have not explored these aspects in the present study, biases in ET partitioning may also carry implications for the simulated carbon cycle: because transpiration is coupled to the carbon cycle through photosynthesis, systematic underestimation of transpiration means that Earth system model simulations of the carbon cycle, in particular of the land carbon sink, may also be biased in some systematic ways-or perhaps other parts of Earth system models are compensating for transpiration biases in an ad hoc manner.

Finally, we have shown that despite very large model diversity in the simulation of present-day ET partitioning, models project consistent changes in partitioning in the future. While all three ET components tend to change in similar directions (in absolute terms) in many regions of the middle to high latitudes and the dry subtropics, in the tropics, models project a clear pattern of decreased transpiration and increased soil evaporation, both in fractions and in absolute terms. This decrease in transpiration is clearly attributable to the physiological impact of $\mathrm{CO}_{2}$ increase, which induces stomatal closure. Overall, future changes in partitioning are caused by a mix of radiatively and physiologically driven processes that affect the components of ET in different ways in different regions. This underscores the complexity of the evaporation response to global warming on land, and the challenges of both accurately capturing that response in numerical models and accounting for it in idealized models of the water and climate system (e.g., Byrne and O'Gorman 2016). This challenge is all the more critical in that this response represents a key element of future climate change: for instance, here we found, consistently with previous studies (e.g., Kooperman et al. 2018), that part of the precipitation response to anthropogenic forcing in the tropics is due to physiologically induced decreases in transpiration. More generally, previous studies have highlighted the role of land evaporation changes in land regional climate change (e.g., Berg et al. 2015) but also in large-scale land-ocean contrasts in response to warming (e.g., Berg et al. 2016) and in aspects of the global hydrological cycle response to $\mathrm{CO}_{2}$ (e.g., 
DeAngelis et al. 2016). Correct representation of changes in land evaporation, and thus in its components, is thus essential for projections of global climate change.

Overall, our results highlight model differences in the simulation of ET partitioning. Given the importance of this partitioning for the simulation of the terrestrial water, energy, and carbon cycle in the present and in future climate, our study points to the critical need to better evaluate, and ultimately improve, the processbased representation of ET partitioning in Earth system models.

Acknowledgments. This work was supported by NOAA Grant NA15OAR4310091. We acknowledge the World Climate Research Programme's Working Group on Coupled Modelling, which is responsible for CMIP, and we thank the climate modeling groups (listed in Table S1 of this paper) for producing and making available their model output. For CMIP the U.S. Department of Energy's Program for Climate Model Diagnosis and Intercomparison provides coordinating support and led development of software infrastructure in partnership with the Global Organization for Earth System Science Portals.

\section{REFERENCES}

Anav, A., and Coauthors, 2013: Evaluating the land and ocean components of the global carbon cycle in the CMIP5 Earth system models. J. Climate, 26, 6801-6843, https://doi.org/ 10.1175/JCLI-D-12-00417.1.

Berg, A., B. R. Lintner, K. L. Findell, S. Malyshev, P. C. Loikith, and P. Gentine, 2014: Impact of soil moisture-atmosphere interactions on surface temperature distribution. J. Climate, 27, 7976-7993, https://doi.org/10.1175/JCLI-D-13-00591.1.

_- and Coauthors, 2015: Interannual coupling between summertime surface temperature and precipitation over land: Processes and implications for climate change. J. Climate, 28, 1308-1328, https://doi.org/10.1175/JCLI-D-14-00324.1.

— , and Coauthors, 2016: Land-atmosphere feedbacks amplify aridity increase over land under global warming. Nat. Climate Change, 6, 869-874, https://doi.org/10.1038/nclimate3029.

Byrne, M. P., and P. A. O'Gorman, 2016: Understanding decreases in land relative humidity with global warming: Conceptual model and GCM simulations. J. Climate, 29, 9045-9061, https://doi.org/10.1175/JCLI-D-16-0351.1.

Chang, L.-L., and Coauthors, 2018: Why do large-scale land surface models produce a low ratio of transpiration to evapotranspiration? J. Geophys. Res. Atmos., 123, 9109-9130. https:// doi.org/10.1029/2018JD029159.

Cheruy, F., J. L. Dufresne, F. Hourdin, and A. Ducharne, 2014: Role of clouds and land-atmosphere coupling in midlatitude continental summer warm biases and climate change amplification in CMIP5 simulations. Geophys. Res. Lett., 41, 64936500, https://doi.org/10.1002/2014GL061145.

Coenders-Gerrits, A. M. J., R. J. Van der Ent, T. A. Bogaard, L. Wang-Erlandsson, M. Hrachowitz, and H. H. G. Savenije, 2014: Uncertainties in transpiration estimates. Nature, 506, E1, https://doi.org/10.1038/nature12925.
Cowan, I. R., 1978: Stomatal behaviour and environment. Adv. Bot. Res., 4, 117-228, https://doi.org/10.1016/S0065-2296(08)60370-5.

DeAngelis, A. M., X. Qu, and A. Hall, 2016: Importance of vegetation processes for model spread in the fast precipitation response to $\mathrm{CO}_{2}$ forcing. Geophys. Res. Lett., 43, 12550 12 559, https://doi.org/10.1002/2016GL071392.

de Noblet-Ducoudré, N., and Coauthors, 2012: Determining robust impacts of land-use-induced land cover changes on surface climate over North America and Eurasia: Results from the first set of LUCID experiments. J. Climate, 25, 3261-3281, https://doi.org/10.1175/JCLI-D-11-00338.1.

Friedlingstein, P., M. Meinshausen, V. K. Arora, C. D. Jones, A. Anav, S. K. Liddicoat, and R. Knutti, 2014: Uncertainties in CMIP5 climate projections due to carbon cycle feedbacks. J. Climate, 27, 511-526, https://doi.org/10.1175/JCLI-D-12-00579.1.

Good, S. P., D. Noone, and G. Bowen, 2015: Hydrologic connectivity constrains partitioning of global terrestrial water fluxes. Science, 349, 175-177, https://doi.org/10.1126/science.aaa5931.

Jasechko, S., Z. D. Sharp, J. J. Gibson, S. J. Birks, Y. Yi, and P. J. Fawcett, 2013: Terrestrial water fluxes dominated by transpiration. Nature, 496, 347-350, https://doi.org/10.1038/nature11983.

Kool, D., N. Agam, N. Lazarovitch, J. L. Heitman, T. J. Sauer, and A. Ben-Gal, 2014: A review of approaches for evapotranspiration partitioning. Agric. For. Meteor., 184, 56-70, https:// doi.org/10.1016/j.agrformet.2013.09.003.

Kooperman, G. J., Y. Chen, F. M. Hoffman, C. D. Koven, K. Lindsay, M. S. Pritchard, A. L. S. Swann, and J. T. Randerson, 2018: Forest response to rising $\mathrm{CO}_{2}$ drives zonally asymmetric rainfall change over tropical land. Nat. Climate Change, 8, 434-440, https://doi.org/10.1038/s41558-018-0144-7.

Lawrence, D. M., P. E. Thornton, K. W. Oleson, and G. B. Bonan, 2007: Partitioning of evaporation into transpiration, soil evaporation, and canopy evaporation in a GCM: Impacts on land-atmosphere interaction. J. Hydrometeor., 8, 862-880, https://doi.org/10.1175/JHM596.1.

Lemordant, L., P. Gentine, A. S. Swann, B. I. Cook, and J. Scheff, 2018: Critical impact of vegetation physiology on the continental hydrologic cycle in response to increasing $\mathrm{CO}_{2}$. Proc. Natl. Acad. Sci. USA, 115, 4093-4098, https://doi.org/10.1073/ pnas. 1720712115.

Lian, X., and Coauthors, 2018: Partitioning global land evapotranspiration using CMIP5 models constrained by observations. Nat. Climate Change, 8, 640-646, https://doi.org/10.1038/ s41558-018-0207-9.

Mahowald, N., F. Lo, Y. Zheng, L. Harrison, C. Funk, D. Lombardozzi, and C. Goodale, 2016: Projections of leaf area index in Earth system models. Earth Syst. Dyn, 7, 211229, https://doi.org/10.5194/esd-7-211-2016.

Maxwell, R. M., and L. E. Condon, 2016: Connections between groundwater flow and transpiration partitioning. Science, $\mathbf{3 5 3}$ 377-380, https://doi.org/10.1126/science.aaf7891.

Miralles, D. G., J. H. Gash, T. R. H. Holmes, R. A. M. de Jeu, and A. J. Dolman, 2010: Global canopy interception from satellite observations. J. Geophys. Res., 115, D16122, https://doi.org/ 10.1029/2009JD013530.

— Evaluation of global terrestrial evaporation data sets. Hydrol. Earth Syst. Sci., 20, 823-842, https://doi.org/10.5194/hess-20823-2016.

Mueller, B., and S. I. Seneviratne, 2014: Systematic land climate and evapotranspiration biases in CMIP5 simulations. Geophys. Res. Lett., 41, 128-134, https://doi.org/10.1002/ 2013 GL058055. 
- and Coauthors, 2013: Benchmark products for land evapotranspiration: LandFlux-EVAL multi-data set synthesis. $H y-$ drol. Earth Syst. Sci., 17, 3707-3720, https://doi.org/10.5194/ hess-17-3707-2013.

Pu, B., and R. E. Dickinson, 2014: Hydrological changes in the climate system from leaf responses to increasing $\mathrm{CO}_{2}$. Climate Dyn., 42, 1905-1923, https://doi.org/10.1007/s00382-013-1781-1.

Riahi, K., and Coauthors, 2011: RCP 8.5-A scenario of comparatively high greenhouse gas emissions. Climatic Change, 109, 33-57, https://doi.org/10.1007/s10584-011-0149-y.

Scheff, J., and D. Frierson, 2012: Twenty-first-century multimodel subtropical precipitation declines are mostly midlatitude shifts. J. Climate, 25, 4330-4347, https://doi.org/10.1175/ JCLI-D-11-00393.1.

Schlesinger, W. H., and S. Jasechko, 2014: Transpiration in the global water cycle. Agric. For. Meteor., 189-190, 115-117, https://doi.org/10.1016/j.agrformet.2014.01.011.

Skinner, C. B., C. J. Poulsen, R. Chadwick, N. S. Diffenbaugh, and R. P. Fiorella, 2017: The role of plant $\mathrm{CO}_{2}$ physiological forcing in shaping future daily-scale precipitation. J. Climate, 30, 2319-2340, https://doi.org/10.1175/JCLI-D-16-0603.1.

Swann, A. L. S., F. M. Hoffman, C. D. Koven, and J. T. Randerson, 2016: Plant responses to increasing $\mathrm{CO}_{2}$ reduce estimates of climate impacts on drought severity. Proc. Natl. Acad. Sci. USA, 113, 10 019-10 024, https://doi.org/10.1073/pnas.1604581113.

Wang, L., K. K. Caylor, J. C. Villegas, G. A. Barron-Gafford, D. D. Breshears, and T. E. Huxman, 2010: Partitioning evapotranspiration across gradients of woody plant cover: Assessment of a stable isotope technique. Geophys. Res. Lett., 37, L09401, https://doi.org/10.1029/2010GL043228.
— S. P. Good, and K. K. Caylor, 2014: Global synthesis of vegetation control on evapotranspiration partitioning. Geophys. Res. Lett., 41, 6753-6757, https://doi.org/10.1002/2014GL061439.

Wei, Z., K. Yoshimura, L. Wang, D. G. Miralles, S. Jasechko, and X. Lee, 2017: Revisiting the contribution of transpiration to global terrestrial evapotranspiration. Geophys. Res. Lett., 44, 2792-2801, https://doi.org/10.1002/2016GL072235.

Williams, D. G., and Coauthors, 2004: Evapotranspiration components determined by stable isotope, sap flow and eddy covariance techniques. Agric. For. Meteor., 125, 241-258, https:// doi.org/10.1016/j.agrformet.2004.04.008.

Williams, I. N., Y. Lu, L. M. Kueppers, W. J. Riley, S. Biraud, J. E. Bagley, and M. S. Torn, 2016: Land-atmosphere coupling and climate prediction over the US Southern Great Plains. J. Geophys. Res. Atmos., 121, 12 125-12144, https://doi.org/ 10.1002/2016JD025223.

Zeng, Z., Z. Zhu, X. Lian, L. Z. Li, A. Chen, X. He, and S. Piao, 2016: Responses of land evapotranspiration to Earth's greening in CMIP5 Earth system models. Environ. Res. Lett., 11, 104006, https://doi.org/10.1088/1748-9326/11/10/104006.

Zhu, Z., and Coauthors, 2013: Global data sets of vegetation leaf area index (LAI) $3 \mathrm{~g}$ and Fraction of Photosynthetically Active Radiation (FPAR) 3g derived from Global Inventory Modeling and Mapping Studies (GIMMS) Normalized Difference Vegetation Index (NDVI3g) for the period 1981 to 2011. Remote Sens., 5, 927-948, https://doi.org/10.3390/ rs5020927.

and Coauthors, 2016: Greening of the Earth and its drivers. Nat. Climate Change, 6, 791-795, https://doi.org/10.1038/ nclimate3004. 